\title{
Research on British and American Culture Development Pattern from the Angles of Metaphor and Idioms
}

\author{
Lijuan Sun \\ School Of Foreign Languages, Zhengzhou University Of Industrial Technology, \\ Henan, 451100 China
}

\begin{abstract}
In this paper, we conduct research on the British and American culture development pattern from the angles of the metaphor and idioms. Cross-cultural communication in English is the most complex sphere in intercultural language communication, and the most typical and representative, which is by number of English speakers and the scope of using English due to ethnic, geographical, historical and social reasons, such as differences in language system, conflict and misunderstanding of cultures and cultural psychology of collision and so on most evident in the modern cross-cultural communication in English. In-depth research on cross-cultural communication aspects of English to eliminate communication misunderstandings will improve the quality of communication as is of great significance. Our research proposes the novel perspectives on the issues that will be meaningful.
\end{abstract}

Keywords- British and American, Culture Development, Pattern, Metaphor and Idioms, Angle.

\section{Introduction}

In recent years, with the development of the modern linguistics, people have gradually realized that foreign language teaching is not only teach the language forms, namely the basic three elements of the phonetics, grammar and vocabulary teaching, in order to make the students speak out rules of the grammar and semantic sentence or reading foreign materials, but also to study the language of social and cultural factors, beyond the language system of the teaching deep man in real life, cultivate the students' cultural awareness or basic cultural sensitivity, and then developed into a kind of the cultural competence, i.e. to use the language of the normal communication with people who speak native language ability. The real task of college English teaching is to let students to recognize limitations of native culture and English culture, break through single cultural stereotype brings to communication barriers, fully express their views, fully understand each other's ideas, in order to achieve equality and meaningful communication and the fundamental purpose of English teaching is not the acquisition of English culture, but the general development of the college students express their culture and ideas of the communicative competence [1-3].

Communicative competence is not abstract, specific communicative competence is the culture of a particular ability. To train the ability of college students' culture, the essence of which is to cultivate their appropriateness of using language, namely the use of language should be suitable for the specific social and the cultural environment. Build curriculum group of British and American literature and culture is on the basis of the integration and optimization of curriculum resources, to point to surface, strengthening the relevance of the course, care of each other, levels clearer, more complete, objective more explicit curriculum knowledge chain advantage, avoid repetition, course content between the boundary is not clear. Based on level one course of the English major students' humanities cultivated manners of general education curriculum system that namely 
knowledge by teaching English country profiles and close reading of literature appreciation, lets the student to analyze the works from view of history, aesthetics, culture, internalizing the humanities spirit, and cultivate consciousness of study.

Years of the college English teaching experience makes us realize that long-term lagging situation makes cross-cultural teaching non-English major college students' English cultural ability is low and the cross-cultural consciousness weak that embodied in the listed aspects. (1) Because of influence of mother tongue mind-set, most of the students in English in oral and written expression, often thinking from the angle of Chinese culture. (2) Some students mistakenly think that cultural knowledge is not included in the university English four, six levels of tests and other large English exam outline with a negative, passive attitude to culture study. (3) Students understanding of English cultural knowledge are limited to literature, history, customs and habits, important festivals, such as surface culture, the communication rules and ways of thinking and values, such as the deep cultures. Specifically, in the figure one, we show the British and American culture comparison [4-5].

\begin{tabular}{|c|c|c|c|}
\hline $\begin{array}{l}\text { British } \\
\text { English }\end{array}$ & $\begin{array}{c}\text { American } \\
\text { English }\end{array}$ & $\begin{array}{l}\text { British } \\
\text { English }\end{array}$ & $\begin{array}{c}\text { American } \\
\text { English }\end{array}$ \\
\hline Aluminium & Aluminum & Ground floor & First floor \\
\hline Aubergine & Eggplant & Guard (on a train) & Conductor \\
\hline Barman & Bartender & Hockey & Field hockey \\
\hline Bath & Bathtub & Jelly & Jello \\
\hline Boot (of a car) & Hood & Jewellery & Jewelry \\
\hline Braces & Suspenders & Herb & Curb \\
\hline Camp bed & Cot & Lift & Elevator \\
\hline Candy floss & Cotton candy & Maize & Corn \\
\hline Caravan & Trailer & Manoeuvre & Maneuver \\
\hline Cobweb & Spiderweb & Mark (for exam) & Grade \\
\hline Cot & Crib & Mince (meat) & Ground beef \\
\hline Crisps & Chips & Moustache & Mustache \\
\hline Courgette & Zucchini & Paraffin & Kerosene \\
\hline Dialling tone & Dial tone & Pay rise & Raise \\
\hline Doll's house & Doll house & Pedestrian crossing & Crosswalk \\
\hline Draught & Draft & Postcode & Zip code \\
\hline Draughts (game) & Checkers & Pram & Baby carriage \\
\hline First floor & Second floor & subway & underpass \\
\hline
\end{tabular}

Figure 1. The British and American Culture Comparison
In this paper, we conduct research on British and American culture development pattern from the angles of the metaphor and idioms. As a social science, the exploration of the English language and literature, in the development of social science has the effect that cannot replace. Language as a major means of human communication, a lot of problems relies on the language. As a kind of language is widely used in the world, English to ease the conflict and promote national communication has a very important role. The current study of English language, no longer limited in level of communication and exchanges, more should pay attention to the breadth and depth of the English language and the content of the integration of other disciplines, etc. In the later sections, we will analyze corresponding topics with theoretical discussion.

\section{Our Proposed Methodology}

The Idioms of the English. Idiom is the language in the process of long-term use of accumulation of the language elements. Anyone who has a long history of language contains a large number of idioms. Idioms are the people verbally commonly used fixed phrases or short sentences.

English idioms also has the characteristics of vivid, image, concise, washes practice, often can be used to express the profound and clear 
ideological content, using proper often can have the effect that make the finishing point. But the overall meaning of English idioms is often the each composition and its literal meaning has certain deviation. Some compared with literal meaning close, some far, some even have nothing to do it is to learn English idioms has brought certain difficulties. In understanding this issue, the English idioms are different from free phrase. The significance of free phrases can be deduced from the part of the literal meaning. The origin of idioms can be summarized as follows.

Idioms and history. The development of the history of language has a significant impact. The trace of historical development is mainly residual in the idioms. Affects the idioms in British history, main historical events is that Romans conquered, Teutonic conquest, Scandinavian invasion, Norman conquests North American colonies independence with two world wars.

Idioms and British literature. Shakespeare, Chaucer, Milton, Coleridge, Byron, and others of dickens' books influence on English idioms are profound. There are many idioms in English from their work and existed literatures [6-7].

Idioms and geography. Specific geographical environment created a certain culture that makes specific idioms. The development of the shipping industry, and the development of the fishing industry, the development of coal industry, the development of animal husbandry more rain misty weather have great influence on English idioms.

Idioms and sports entertainment. Horse racing, poker, boxing, and other sports entertainment projects have a certain influence on idioms.

English idioms in addition to the overall meaning and its surface structure is not consistent, their grammatical functions are often inconsistent with its structure components, especially for the center with the noun form of idioms, it is hard to determine its syntactic function from the perspective of the structure. Cognitive linguistics, especially the cognitive semantics meaning for us to explore idioms has provided a new method has a potential use. It is not hard to see from the perspective of cognitive of idioms is the essence of the conceptual and systematic and the meaning of the idioms are rational according to which is not arbitrary.

The Metaphor. Metaphor is a very common rhetoric, it is everywhere in people's Daily life is full of metaphor in human language. Traditional rhetoric that metaphor is a kind of figures of speech is a kind of modified means of the basic discourse. Cognitive linguistics think it is not only a linguistic phenomenon, it is more important is the human cognitive phenomenon, a way of thinking. It is the human experience of a particular field is used to explain or understand another kind of experience in the field of a kind of cognitive activity. Since human language has the characteristics of metaphor, and one of the English language as a representative of the metaphor of the richest, teaching and learning and can't completely out of metaphor in the process of learning and teaching, particularly vocabulary teaching. The figure two reflects the nature of the metaphor.

\section{The Nature of Metaphor}

- Metaphor is the main mechanism through which we comprehend abstract concepts and perform abstract reasoning.

- Much subject matter, from the most mundane to the most abstruse scientific theories, can only be comprehended via metaphor.

- Metaphor is fundamentally conceptual, not linguistic, in nature.

- Metaphorical language is a surface manifestation of conceptual metaphor.

- Though much of our conceptual system is metaphorical, a significant part of it is nonmetaphorical. Metaphorical understanding is grounded in nonmetaphorical understanding.

- Metaphor allows us to understand a relatively abstract or inherently unstructured subject matter in terms of a more concrete, or at least a more highly structured subject matter.

- From: George Lakoff. The Contemporary Theory of Metaphor.

Figure 2. The Nature of Metaphor

Language is a reflection of the human cognitive ability. The highest goal of language teaching is to cultivate language learner ability to use language, and use the language. Metaphor is 
English learners' understanding of language knowledge and acquisition. Train ability of language learners' metaphor, can deepen the country cultural background knowledge of the target language and national way of the thinking to improve learners' comprehensive language ability is of great significance [8].

The applications scenarios of the metaphor could be summarized as the follows. (1) For the learner of a second language vocabulary learning means that establish and expand the vocabulary, vocabulary knowledge accumulation, and has been consolidated and application of learning vocabulary. The metaphor is generally exists in human daily life, people often refer to the familiar, tangible, concrete are not familiar with the concept of the knowledge, experience and expression, invisible and abstract concepts. (2) Because of the difference of culture, people to the use of lexical meaning and metaphor are subject to their respective cultural rules and constraints, therefore, both in terms of customs and aesthetic point of view, the Chinese and British and American countries people must exist between different metaphorical concepts, cultural cognition of same words often also can appear very different situation. (3) English vocabulary is the same as the Chinese lexical metaphors and the inter-cultural. All human beings rely on external conditions, including geographical conditions and the ecological environment, the seasons, the climate change, and even the entire human society culture background there are a variety of common, the general form of the human and the outside world itself.

The English Linguistics. According to cognitive linguistics, language in various units category, like most of the people had built up category, are discrete as the boundary is not clear. Category refers to the person's thinking a summary of the common features of the objective things, or things in the process of the human thinking, cognitive category, and the cognitive process of classifying objective things. A category of the cognitive process, people can consciously according to the concepts and the principles to understand the basic language of a category. Category in the whole process of human understanding of the English language learning involves vocabulary in the prototype, and preliminary understanding of the concepts and theories. Based on this connection, the metaphor thinking can be interpreted to most everyday words, as a result, the metaphor methods of vocabulary teaching is of the positive significance reflected from the listed aspects. (1) Owing to "divergent", "leap" characteristics of the vocabulary teaching lively and interesting. Metaphor is a common way of thinking the human is also common means of language words and word formation. Through the significance of metaphor can memorize more words in addition, knowledge about the role of the metaphorical thinking in the creation of new meanings of new words that can help students understand the vocabulary from the perspective of the cognitive structure. (2) Many words in English are of polysemy. Because metaphor is an important means of development and extension of the meaning of the polysemy phenomenon by means of metaphor from the center to the other meaning of a word extension process, when learning vocabulary, we should grasp the characteristics of the polysemy comprehensive understanding on the meaning. (3) The basic category words in language cognition are very basic and very important. The basic category words are words syllable is less, not native words, the analysis of the composition has a great deal of arbitrariness in the early, these words are children's first acquisition, many subordinate word derived from the basic category of the word, the basic category words than any other of category words with more metaphorical usages [9-10].

The Culture Development Pattern. In the process of the culture teaching in the foreign language teaching is language teaching, to teach and learn target language countries related cultural knowledge content, process and methods of the teaching. China English is not only 
important language teaching form and content, form and content is also an important cultural teaching. Chinese English as carrying English expression of Chinese culture naturally became the indispensable language of instruction in culture teaching. The close ties between language and the culture. Indeed, the content of the language with culture, language is the carrier of culture; Culture expressed by language, various elements of their culture is reflected in language, the two sides. Anyone in the definition of culture that is a guess, generally there are broad sense and narrow sense. Generalized culture refers to the human in process of social and historical development created by the sum total of material wealth and spiritual wealth. Narrow sense of culture is refers to the human culture value created by knowledge system, it includes knowledge, belief, art, morals, law, custom, etc.

Because of this the concealment and complexity, and the objective existence of cultural adaptation, people tend to ignore the fact that all people are familiar with is not the result of external teaching, but the product of the surrounding culture. College students of British and American culture identity once established, they will eliminate prejudice and hostility, learn to recognize, accept and tolerate other countries' culture can continue to expand their cultural field of vision, gradually improve their culture ability, so as to achieve the ultimate goal of English language research.

\section{Conclusion}

In this paper, we conduct research on the British and American culture development pattern from the angles of the metaphor and idioms. Due to the communication strategy are there differences due to the different cultures, so people from heterogeneous cultures while using the same language system to communicate will create difficulties and problems. In order to achieve the communicative purpose, achieve good communication effect, avoid misunderstandings, glaring and communication of culture in the cultural factors of psychological sensitive situation and regional, distinguish between different communication objects, take effective communication strategy, establish appropriate communication relationship is especially important, it relates to the success or failure of communication in the very great degree and the quality of the information. Under this guidance, we combine the metaphor and idioms to propose our understanding of the British and American culture development pattern.

\section{References}

[1] He, C. U. I. "Understand the British and American Culture Background To improve the English Comprehensive Quality." Overseas English 12 (2012): 029.

[2] Baldwin, Clive. "Post-World War II Masculinities in British and American Literature and Culture: Towards Comparative Masculinity Studies." Contemporary Women's Writing (2014): vpu009.

[3] Marshall, David B. "Transatlantic Methodists: British Wesleyanism and the Formation of an Evangelical Culture in Nineteenth-Century Ontario and Quebec by Todd Webb (review)." The Canadian Historical Review 96.1 (2015): 120-122.

[4] Conboy, Martin. "Joel H. Wiener. The Americanization of the British Press, 1830s-1914: Speed in the Age of Transatlantic Journalism." The American Historical Review 118.2 (2013): 582-583.

[5] Morgan, Kenneth. "'Merely for Money'? Business Culture in the British Atlantic, 1750-1815 by Sheryllynne Haggerty (review)." Enterprise \& Society 15.4 (2015): 923-925.

[6] Liao, Haiyan. "The study of the open-type multiple appraisal models in British and American Literature Course from the 
respective of general education." 3rd International Conference on Science and Social Research (ICSSR 2014). Atlantis Press, 2014.

[7] Morin, Emily. "The Late Works of Dame Ethel Smyth: A Musical Microcosm of Interwar British Culture." (2015).

[8] Molthan-Hill, Petra. "The moral muteness of managers An Anglo-American phenomenon? German and British managers and their moral reasoning about environmental sustainability in business." International
Journal of Cross Cultural Management 14.3 (2014): 289-305.

[9] Jay, Mandy, et al. "British Iron Age chariot burials of the Arras culture: a multi-isotope approach to investigating mobility levels and subsistence practices." World Archaeology 45.3 (2013): 473-491.

[10]Gibson, Marion. "Vikings and victories: sea-stories from 'The seafarer' to Skyfall and the future of British maritime culture." Journal for Maritime Research 17.1 (2015): $1-15$. 